\title{
Construction of Tooth Positioners with LTV Vinyl Silicone Rubber and Some Case Reports
}

\author{
by \\ Katsuyuki KAMADA* and Minoru NISHIYAMA**
}

\section{Introduction}

In the orthodontic field, attention has recently begun to center on active treatment with tooth positioners, appliances with elasticity made of rubber materials used for orthodontic force in place of conventional metal wires[1-7].

Tooth positioners were contrived by KeSLING as retainers to be used after the use of metal wires in active treatment $[8,9]$. Nowadays, it is used for closing the spaces due to band removal after active treatment, for the minute regulation of the occlusal relationship and for aftercare as a retainer. Not only that, as it is possible to regulate malocclusion by moving teeth with rubberlike elasticity applied in place of metal wires or brackets, it is beginning to draw attention as a new active treatment appliance to be substituted for conventional metal wires.

With regard to the materials for tooth positioners to be used as active treatment appliances, various kinds of materials have been applied since KESLING contrived them[10-12], but few materials satisfy the necessary conditions for tooth positioners[10]; 1) easy manipulability, 2) elasticity and hardness, 3) tastelessness and odorlessness in the oral cavity and 4) durability. Polyurethane rubber and heatvulcanized silicone (HTV) rubber which are tasteless, odorless and superior in elasticity, have recently been developed[1,4-7], but these materials require special mold materials and equipment in the preparation process which is also very complicated, so their use has not been widespread as yet.

Therefore, for several years the authors have been studying their practical application and trying to develop a material that is easy to manipulate and superior in physical properties $[2,3,13]$. As a result, the authors have developed a clinically applicable method of tooth positioners with low temperature vulcanized (LTV) vinyl silicone rubber. The following is an outline of its physical properties, the method for its preparation and some case reports.

\section{Materials and Properties}

Though silicone rubber is roughly classified into two types (HTV rubber and room temperature vulcanized (RTV) rubber), the silicone rubber that the authors have introduced into the dental field[13] is not HTV rubber that requires a high temperature to vulcanize (1st vulcanization $150^{\circ} \mathrm{C}$ and 2 nd vulcanization $250^{\circ} \mathrm{C}$,

\footnotetext{
*鎌田勝之: Dept. of Orthodontics, Nihon University School of Dentistry, Tokyo, Japan.

**西山 實: Dept. of Dental Materials, Nihon University School of Dentistry, Tokyo, Japan.
} 
Table 1 Physical properties of LTV vinyl silicone rubber (T-Fix)

\begin{tabular}{lcc}
\hline \multicolumn{1}{c}{ Item } & Regular type & Hard type \\
\hline Specific Gravity & 1.12 & 1.21 \\
Hardness (Shore Hardness)* & 43 & 55 \\
Tensile Strength $\left(\mathrm{kg} / \mathrm{cm}^{2}\right)^{*}$ & 50 & 58 \\
Elongation $(\%)^{*}$ & 380 & 240 \\
Young's Modulus $\left(\mathrm{kg} / \mathrm{cm}^{2}\right)$ & 16 & 28 \\
Elastic Strain $(\%)$ & 3.6 & 2.7 \\
Permanent Deformation $(\%)$ & 0.1 & 0.1 \\
Water Absorption $\left(\mathrm{mg} / \mathrm{cm}^{2}\right)^{* *}$ & 0.02 & 0.02 \\
\hline
\end{tabular}

* Storage in $37^{\circ} \mathrm{C}$ water, 90 days

** Storage in $37^{\circ} \mathrm{C}$ water, 30 days

but LTV vinyl silicone rubber $\left(\right.$ T-Fix) ${ }^{\mathrm{a}}$ that vulcanizes at $80-150^{\circ} \mathrm{C}$. Some facts about the material are as follows:

1. Composition

The base material is a thixotropic paste of dimethylvinyl siloxy polydimethylsiloxane: Vi-PDMS, with chloroplatinic acid: $\mathrm{H}_{2} \mathrm{PtC}_{6}$ (catalyst) added, and the hardener is a liquid composed of polyhydromethylsiloxane: PHMS and Vi-PDMS.

2. Mix ratio and vulcanization

The standard mixing ratio of the base material and the hardener is 10:1 (weight percent), and the mixture has a 24-hour pot life at room temperature $\left(25^{\circ} \mathrm{C}\right)$.

Vulcanization finishes in a short time $\left(20\right.$ minutes at $100^{\circ} \mathrm{C}$ and 10 minutes at $150^{\circ} \mathrm{C}$ ), when the mold materials have good thermal conduction, but in the case of plaster molds in a water bath, using a dental flask, the adequate vulcanizing time is $60-90$ minutes at $100^{\circ} \mathrm{C}$.

The vulcanization mechanism is an addition polymerization[13], and no byproducts are produced. Consequently, shrinkage due to vulcanization can hardly be seen. But careful treatment is necessary because its vulcanization is liable to be incomplete if it comes in contact with either sulfer, phosphorus, nitrogen compound, organometallic salt or flux.

3. Harmfulness

The present material is not considered harmful. It has passed notification test No. 434 issued by the Ministry of Health and Welfare in Japan. Furthermore, the authors are convinced, from the data obtained through the clinical application of the tooth positioner made of the present material, that it does not cause redness or tumors of the oral mucosa nor does it cause an uncomfortable feeling when applied.

4. Physical properties of the set product

There are two types of the present material; regular and hard. Table 1 shows the physical properties of the respective set products.

\section{Method for Preparing a Tooth Positioner}

The method for preparing a tooth positioner with LTV vinyl silicone rubber (T-Fix) is as follows: The working process, from set-up model to wax model for mak- 
ing a tooth positioner, follows the conventional method[5,8-10], but the subsequent process was contrived by the authors.

1. Preparing a set-up model

In the process of preparing tooth positioners, the first thing to do is to make a set-up model of the supposed dental arch after treatment. A set-up model is prepared by separating the upper and lower plaster models and arranging them in the ideal position to serve the purposes of treatment. The method is as follows:

1) Making plaster models

Plaster models are prepared by taking impressions of the patient's upper and lower jaws with alginate impression material. First, an ordinary plaster mixture is filled to a height of 5-8 $\mathrm{mm}$ from the cervial upper margin to be cured. After curing, a separator is applied up to the molar portions and then the models are filled with an $\alpha$-plaster mixture. The application of the separator is to get a horizontal division, a standard level on the plaster model, separating the dental arch and base, which is necessary in preparing set-up models.

2) Mounting the plaster model on an articulator

The trimmed plaster model is mounted on an articulator to reproduce occlusal conditions.

3) Die division

The dental arch is separated from the division line of the model (Fig. 1). After the dental formula is written on the labial surface of each die, the dental arch is separated at the contact surface of the lower central incisor using a fretsaw in the direction of root to crown in accordance with the principle of rearrangement. Next, each die in an irregular position on the separated dental arch is cut from the root section to just before the contact point (Fig. 2) to be separated with fingers (Fig. 3).

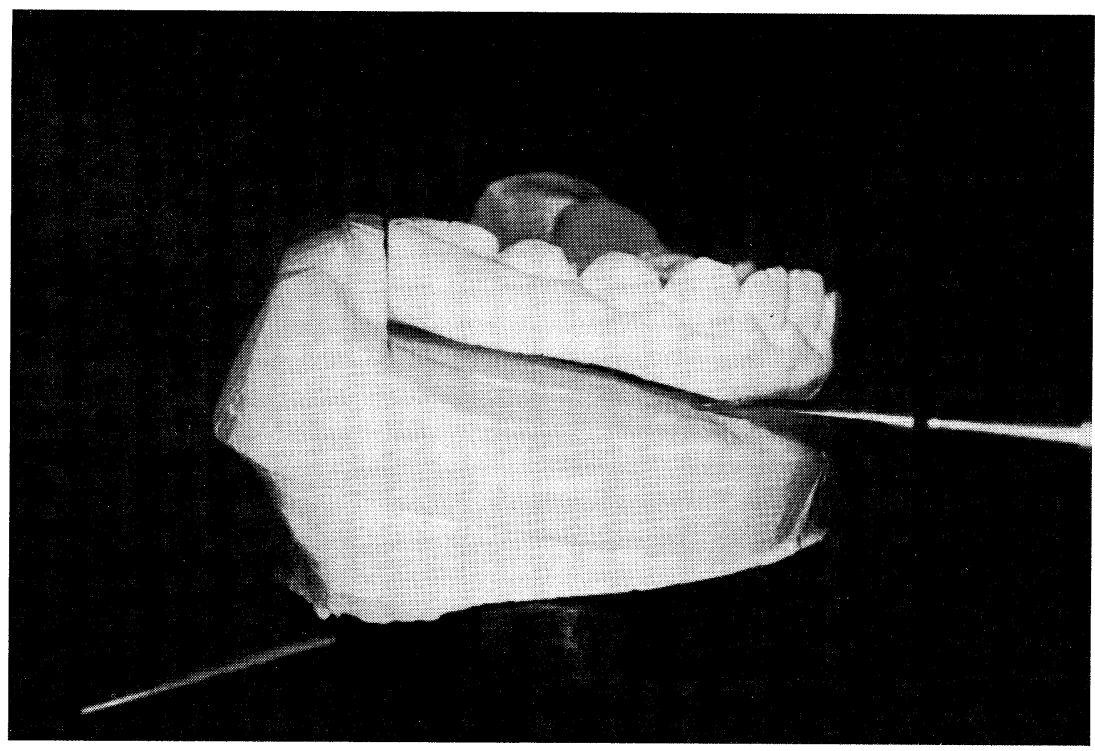

Fig. 1 Separation between a part of the dental arch and base 


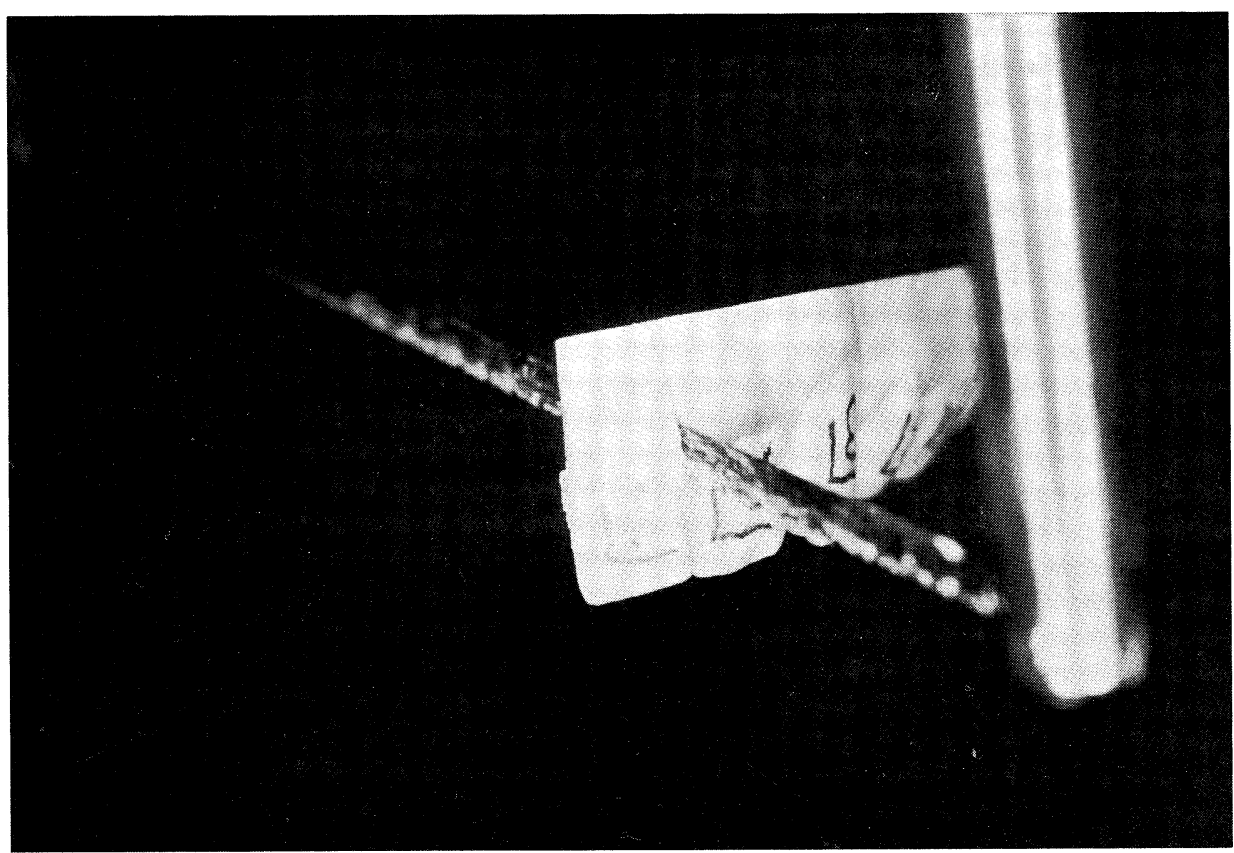

Fig. 2 Vertical separation of the dental arch by the use of a fretsaw

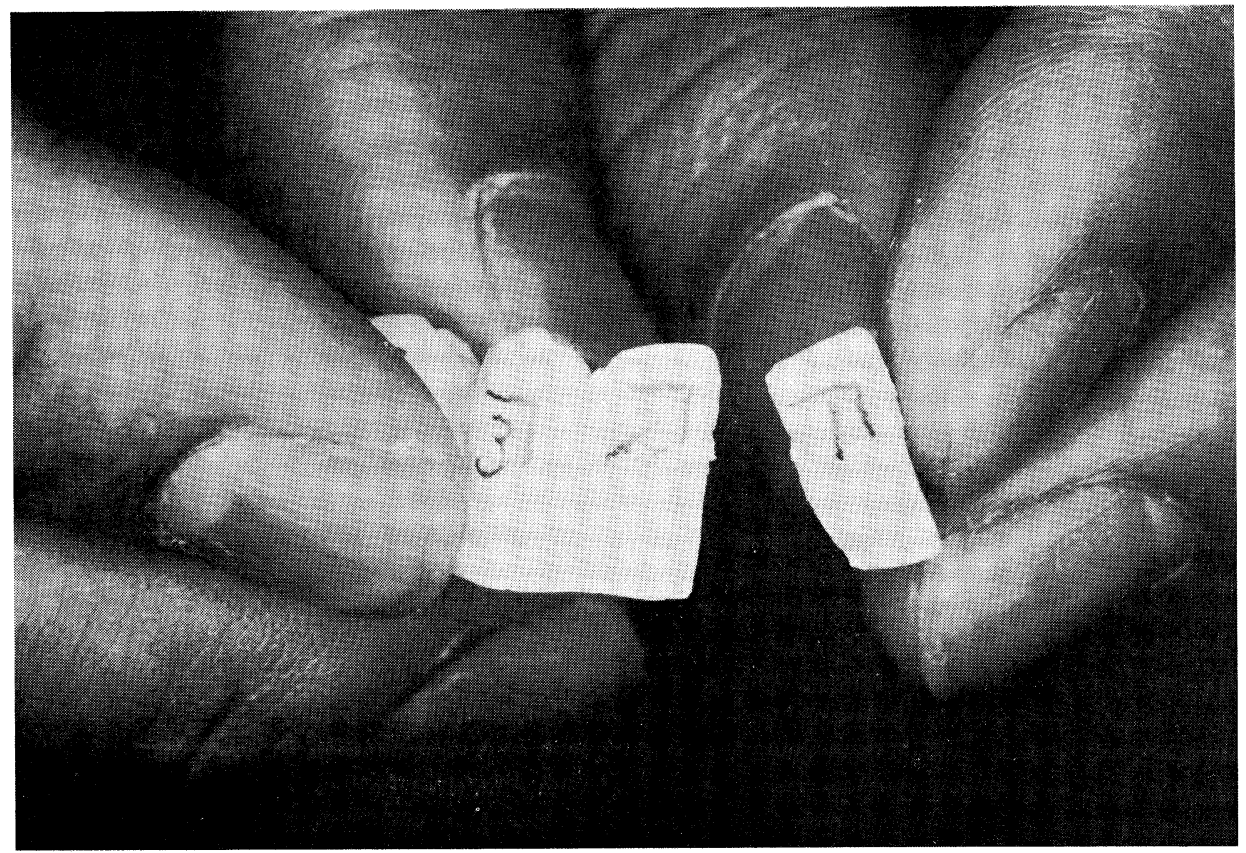

Fig. 3 Individual separation with fingers 


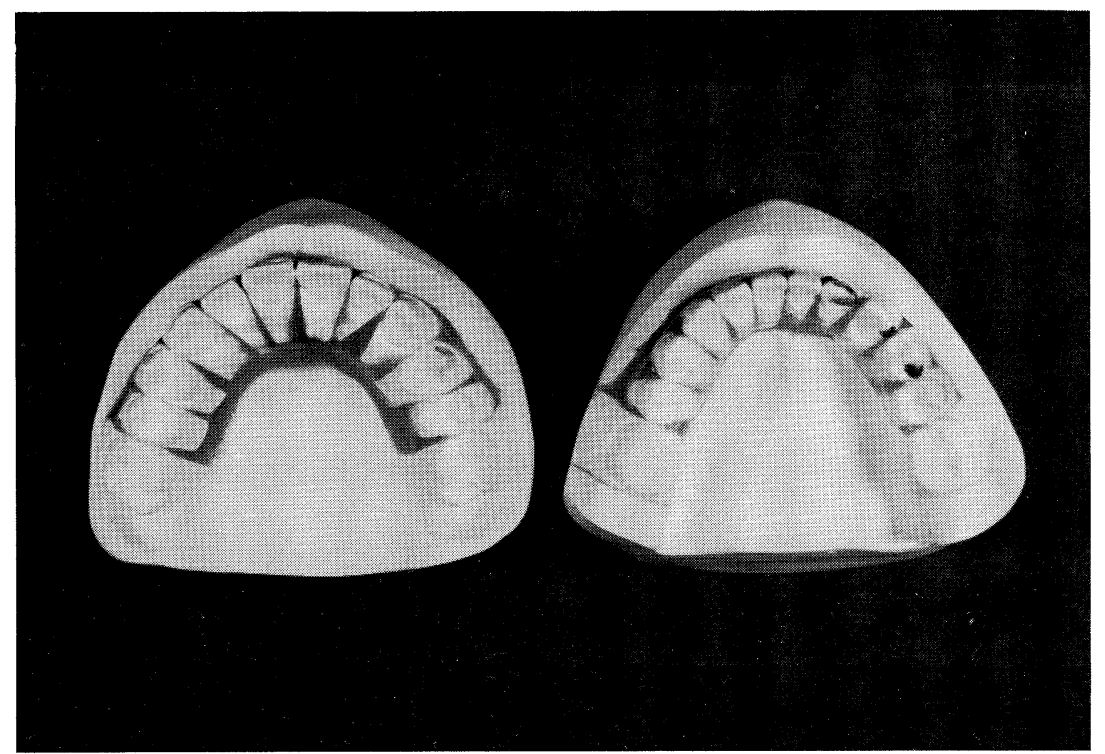

Fig. 4 Set-up models

The portions or numbers of teeth to be separated is decided according to the purpose or plan for treatment. The mesiodistal surface of each separated die is individually carved to make the die root similar to a normal root and each die base is reduced by $2 \mathrm{~mm}$.

4) Die rearrangement

The separated dies are rearranged in accordance with the treatment plan on the articulator. To move the teeth, the aim points are put on the opposite side. So, the rearrangement is carried out from one side of the lower dental arch to the other. The rearranged dies are fixed with paraffin wax, referring to the gingival condition before separation, and then with the lower dental arch used as standard, one side of the upper dental arch is rearranged and then the other. Finally, wax gum festooning is performed to complete the set-up model (Fig. 4).

Then, using the set-up model mounted on the articulator, bite raising is carried out, approximately $4 \mathrm{~mm}$ at the anterior tooth portion, to take a wax bite.

2. Making working models

The set-up model is duplicated with alginate impression material and an $\alpha$-plaster mixture is filled into the impression surface to make a working model (Fig. 5).

3. Making a wax model of the tooth positioner

The upper and lower working models are fixed with the wax bite taken in 1 . 4), to make a wax model of the tooth positioner (Fig. 6).

4. Making a plaster mold

Wax models, invested in plaster with a dental flask in accordance with the conventional method, is soldered to be a plaster mold, to which an alginate separator is applied. . . . Even without an alginate separator, the silicone product is easily taken 


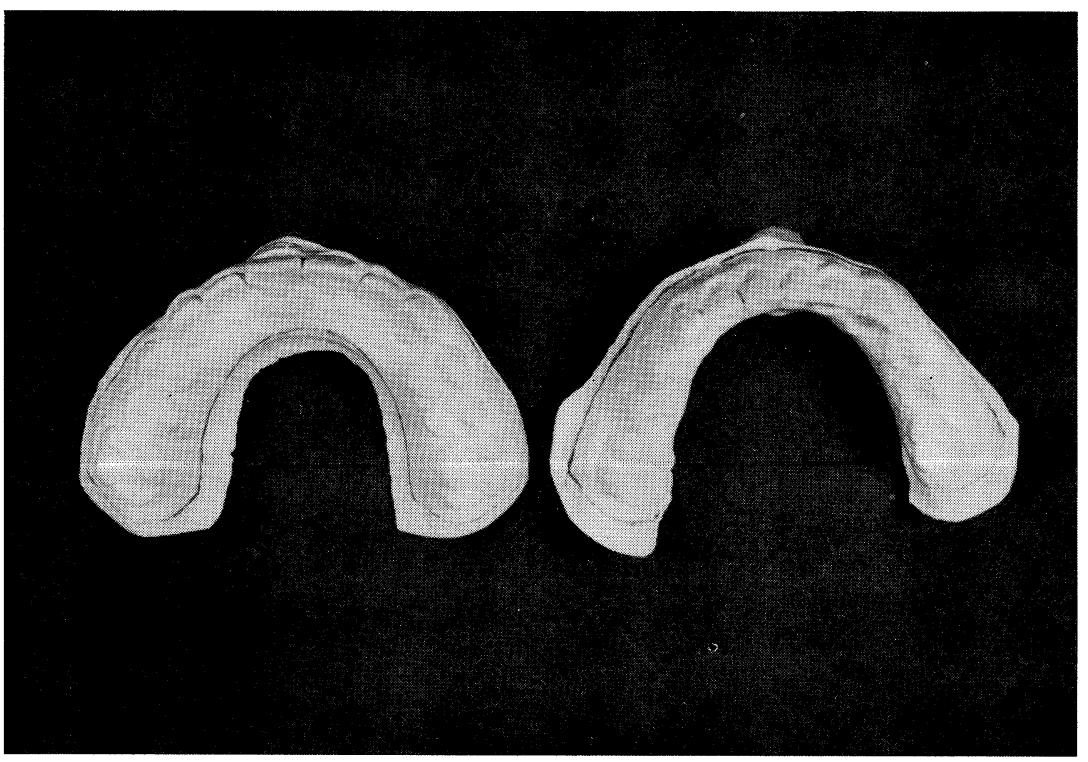

Fig. 5 Working models

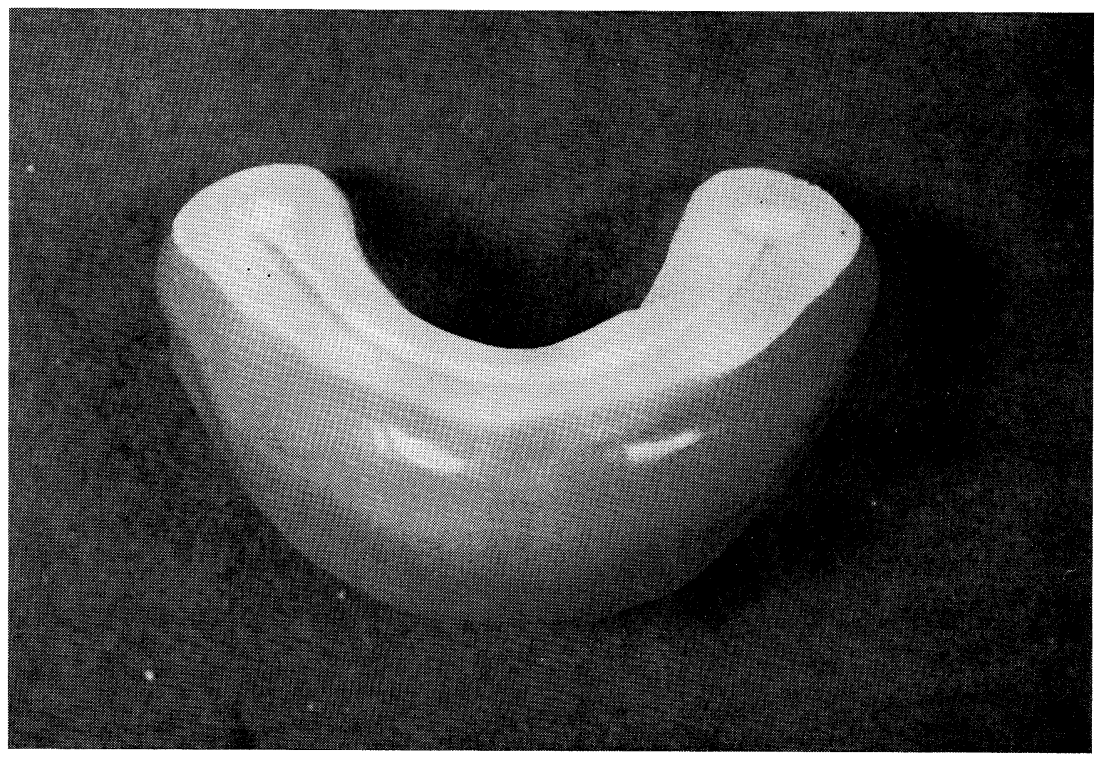

Fig. 6 Wax model of a tooth positioner 

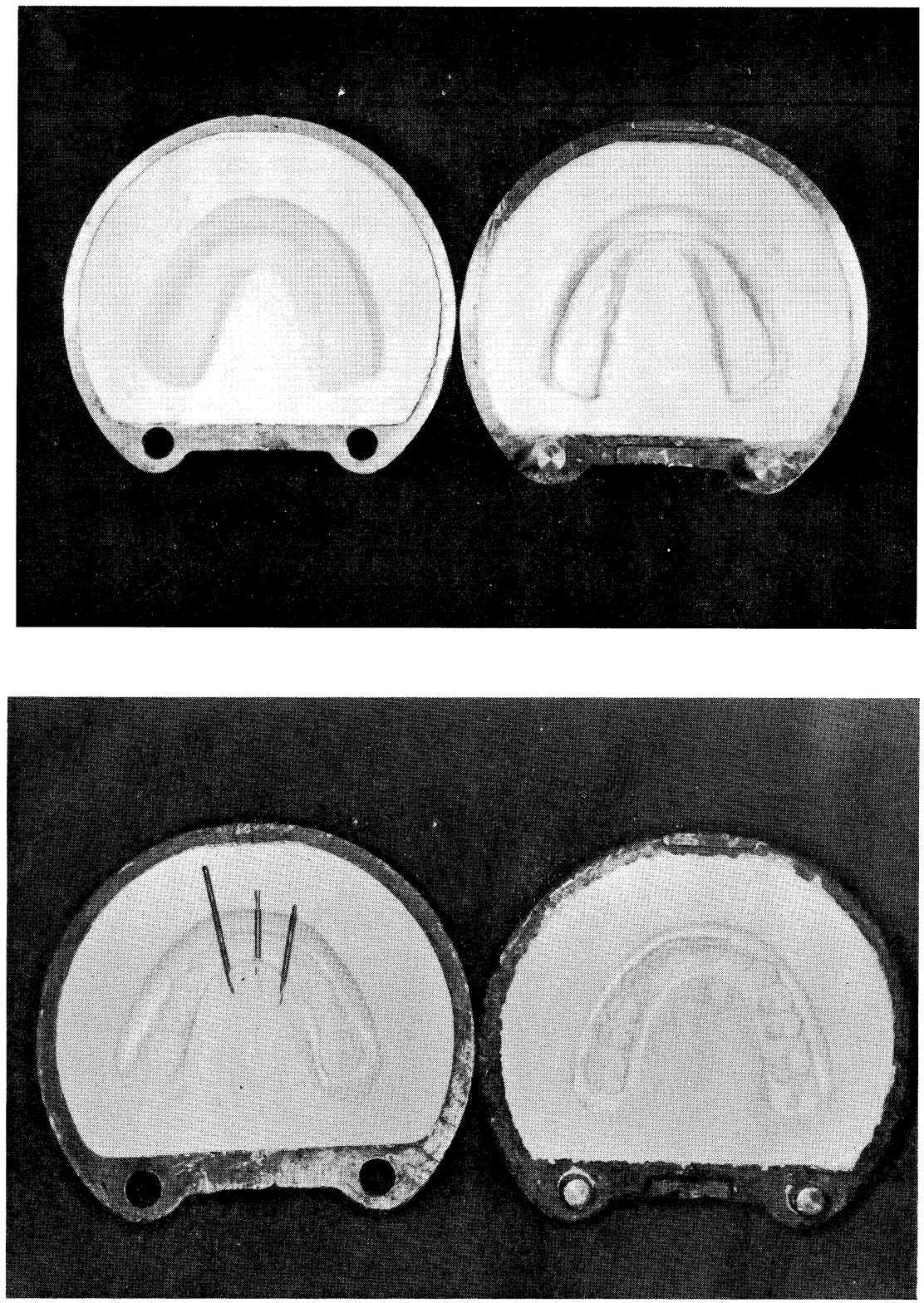

Fig. 7 Split plaster molds

out of the mold, but the lubricity of the set product surface seems to be somewhat inferior as compared with those with an alginate separator applied.

On the other hand, as shown in Fig. 7, bottom, the tooth positioner when completed may have some air holes between the upper and lower incisal edges if $2 \mathrm{~mm}$ $\phi$ wires are inserted beforehand when the wax model is made. 
5. Filling with a silicone mixture

The base material and hardener are well mixed in a ratio of 10:1 and then the plaster mold is filled with the silicone mixture (Fig. 8) with a syringe (Figs. 9, 10). The silicone mixture is thixotropic and easily pushed out into the mold with a syringe or piled up in the mold with a spatula. Again, as the mixture has a 24-hour pot life at room temperature there is no hurry about the manipulation of mixing and filling. 6. Vulcanization of silicone

After finishing the filling of the mixture the flask, with both trays put together, is pressed at $\left(50-60 \mathrm{~kg} / \mathrm{cm}^{2}\right)$ and is held with a clamp and heated in a $100^{\circ} \mathrm{C}$ water bath for $60-90$ minutes. Dry heating is also allowed. If a polymerization pressure fot for dentures is used, the heating time can be shortened to 10 minutes.

7. Takeout and polish

When vulcanization is completed the flask is taken out of the water bath to be cooled, still clamped. It is not always necessary to leave it to cool at room temperature. Quick cooling in water does not have any effect on the set product.

Vulcanized silicone, when cooled, having preferable elasticity, is easily taken out of the flask with its upper and lower trays split (Figs. 11, 12). Again, there is no fear of injuring the plaster mold in the takeout precess, so the same plaster mold can produce more than two tooth positioners.

Flashes due to the splitting of the mold are very thin $(30-50 \mu)$, and there is little fear of causing dimensional changes in the height of the bite.

Polishing is almost unnecessary. The flashes are cut with scissors and their traces are restored with sandpaper cones to complete the tooth positioner (Figs. 13, 14). It is possible to increase the lubricty of the surface, if necessary, by coating it with glazing silicone (Fig. 15) and leaving it in the drier for 30 minutes at $100-130^{\circ} \mathrm{C}$ (Figs. 16, 17).

The merits of preparing tooth positioners with LTV vinyl silicone (T-Fix) are as follows:

1) The plaster mold is easily filled with the mixture with either a syringe or spatula.

2) The mixture, having a 24-hour pot life at room temperature, is extremely preferable in manipulation.

3) Vulcanization is completed in 60 minutes at $100^{\circ} \mathrm{C}$.

4) The set product is tasteless and odorless and shows preferable rubber-like elasticity.

5) There is no need for special mold materials; plaster molds will produce preferable set products.

6) The set product is easily taken out of the plaster mold.

7) There is no fear of injuring the plaster mold in the takeout process, so the same mold can produce more than two set products.

8) Set product surfaces have good lubricity.

9) Flashes due to the splitting of the mold are very thin $(30-50 \mu)$, and there is little fear of causing dimensional changes in the height of the bite.

10) Partial arrangement of materials, different in mechanical strength, is possible. 


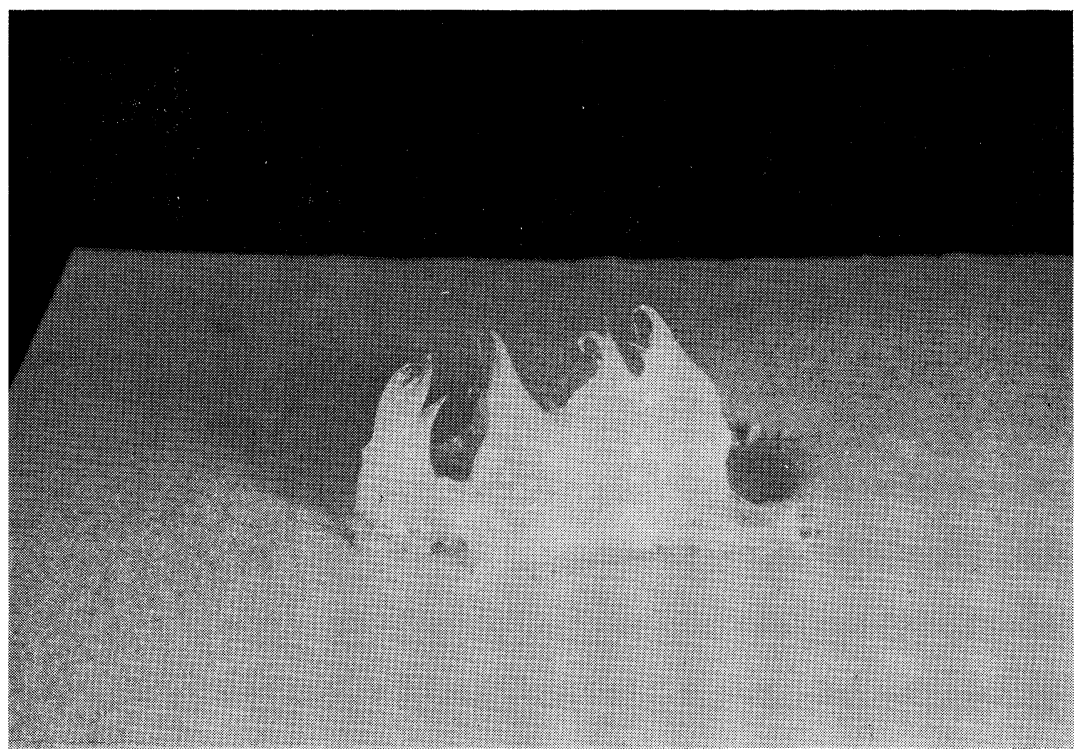

Fig. 8 LTV vinyl silicone mixture

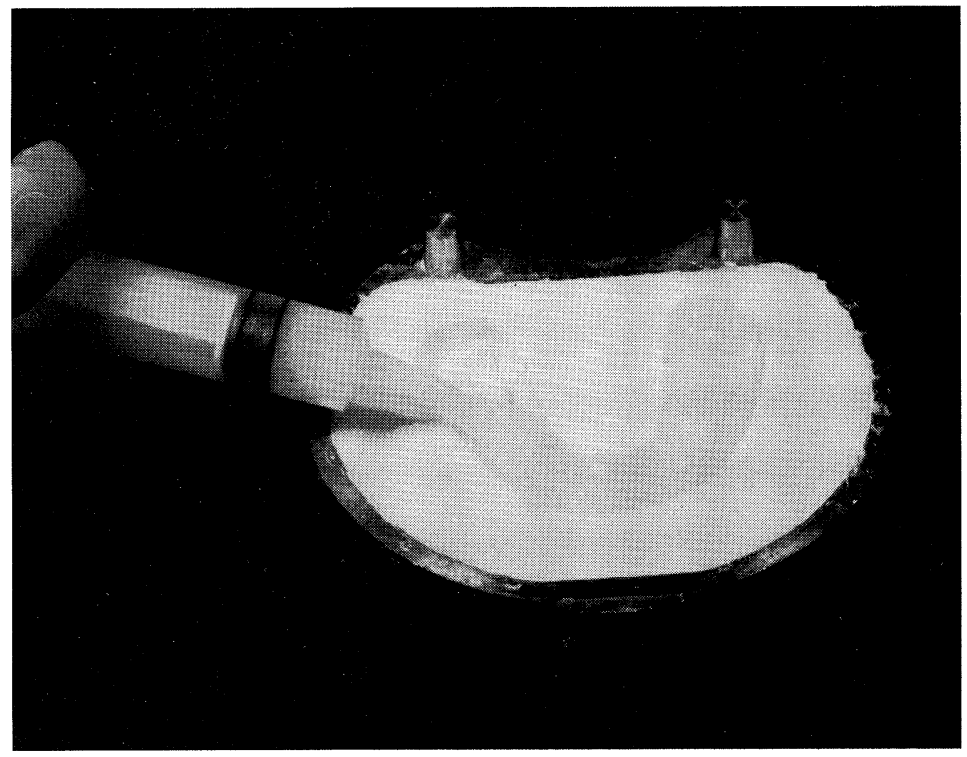

Fig. 9 Mixture is filled into mold by syringe 

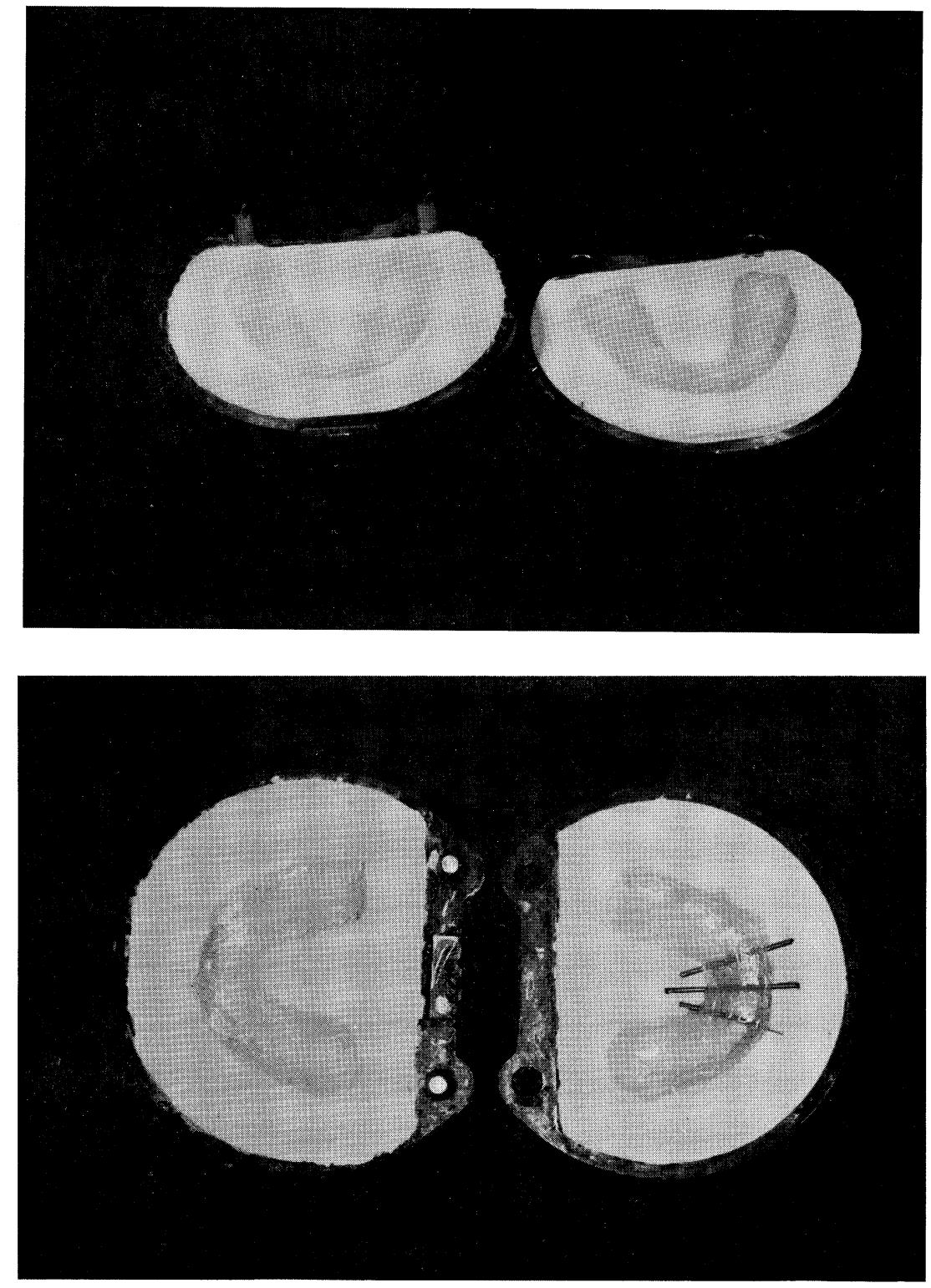

Fig. 10 Mixture is filled 

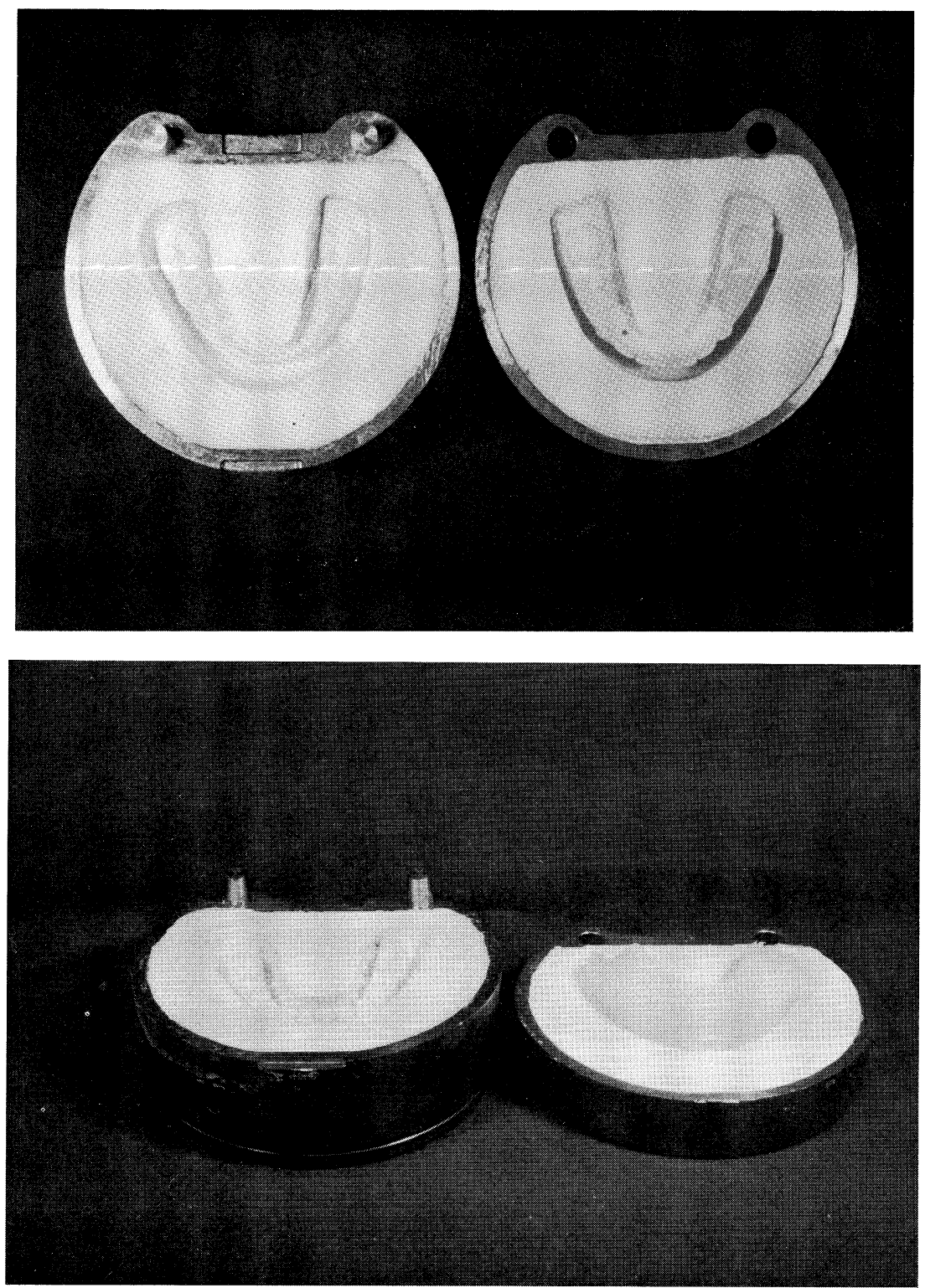

Fig. 11 After curing flasks are separated 

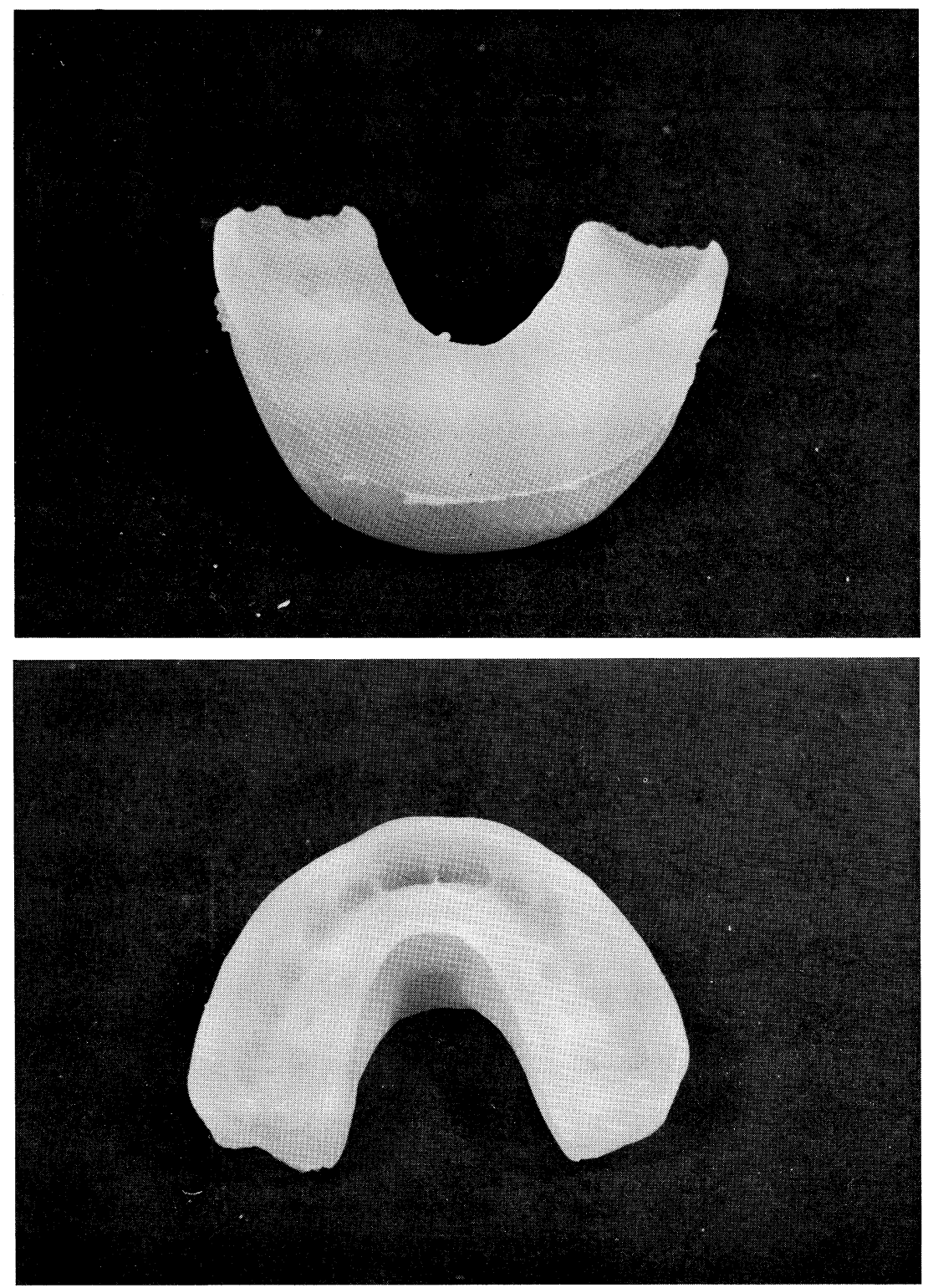

Fig. 12 Tooth positioner immediately after takeout 

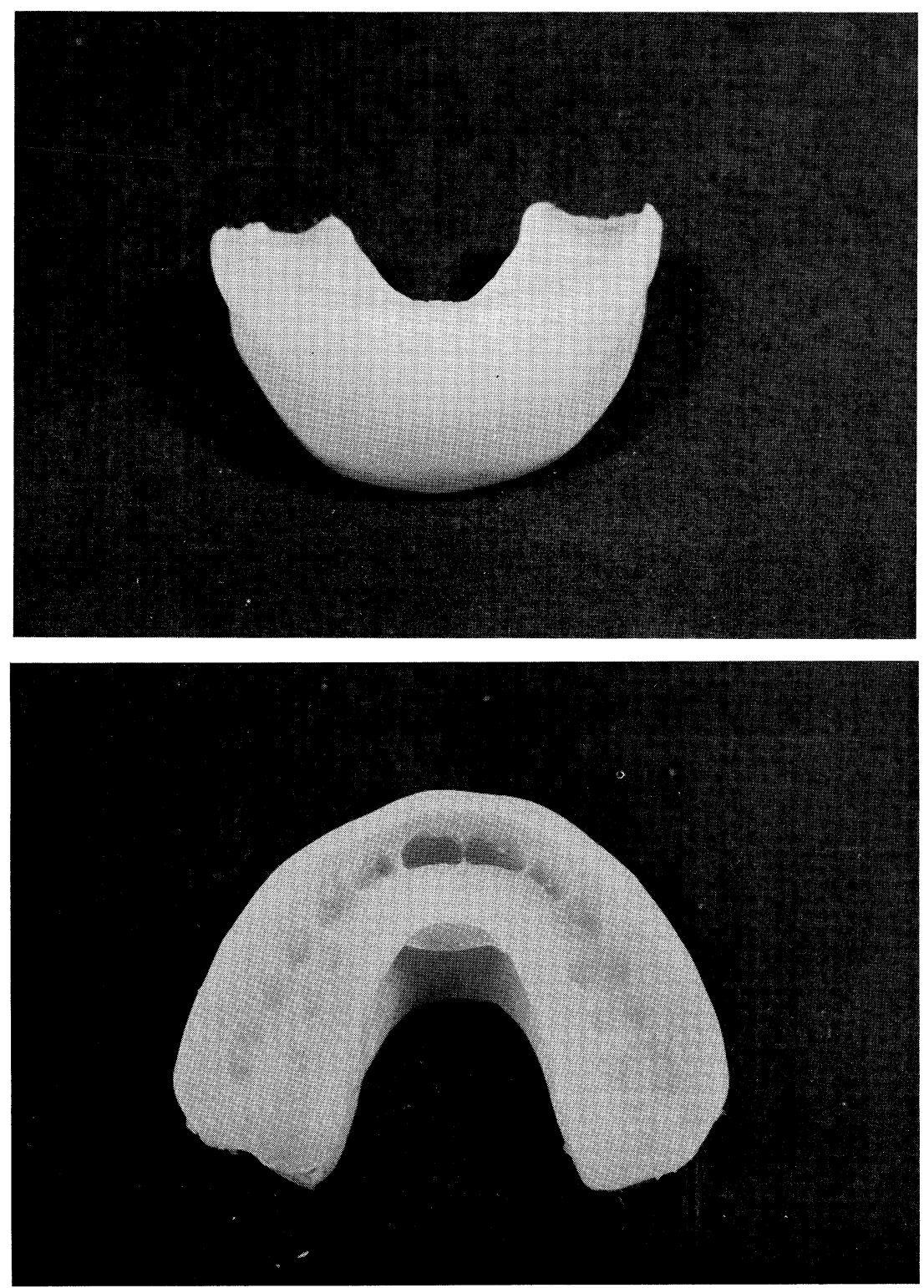

Fig. 13 Completed tooth positioner (Regular type) 

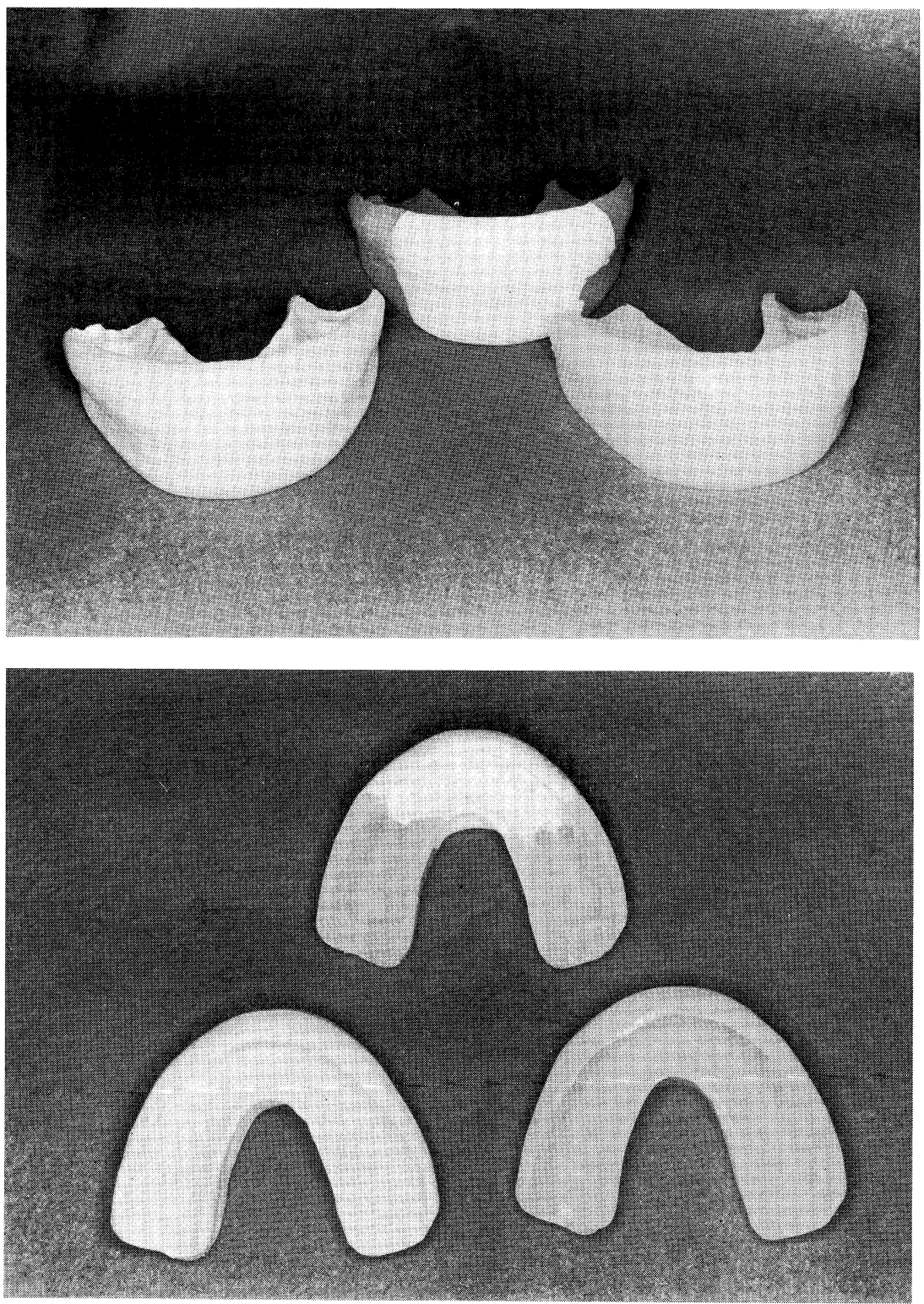

Fig. 14 Completed tooth positioners (Left: hard type, Center: combination of regular and hard types, Right: regular type) 


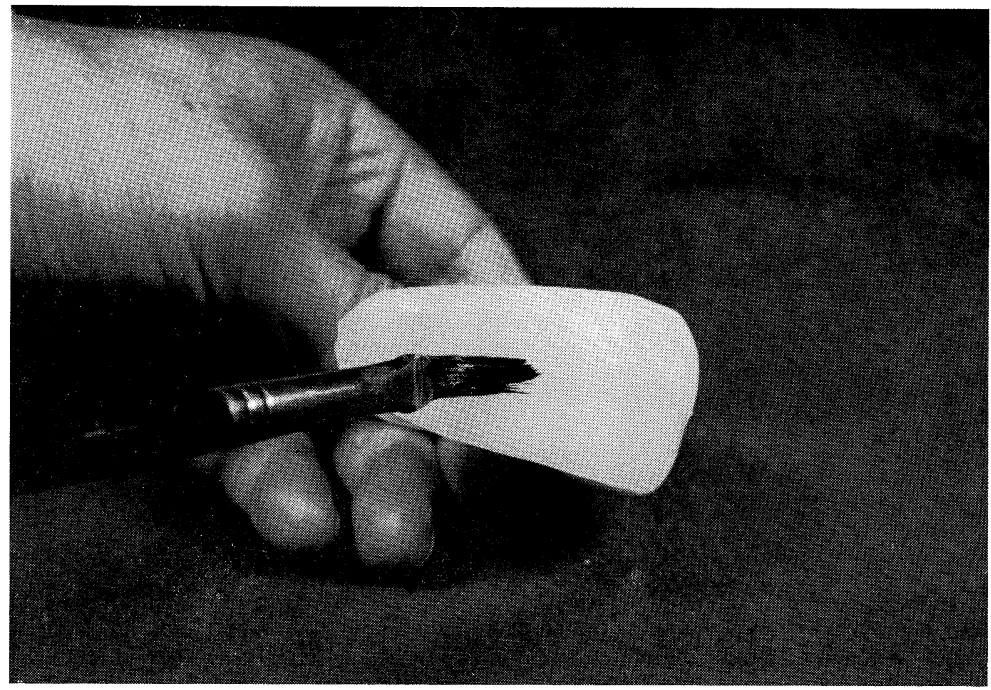

Fig. 15 Coating of glazing agent

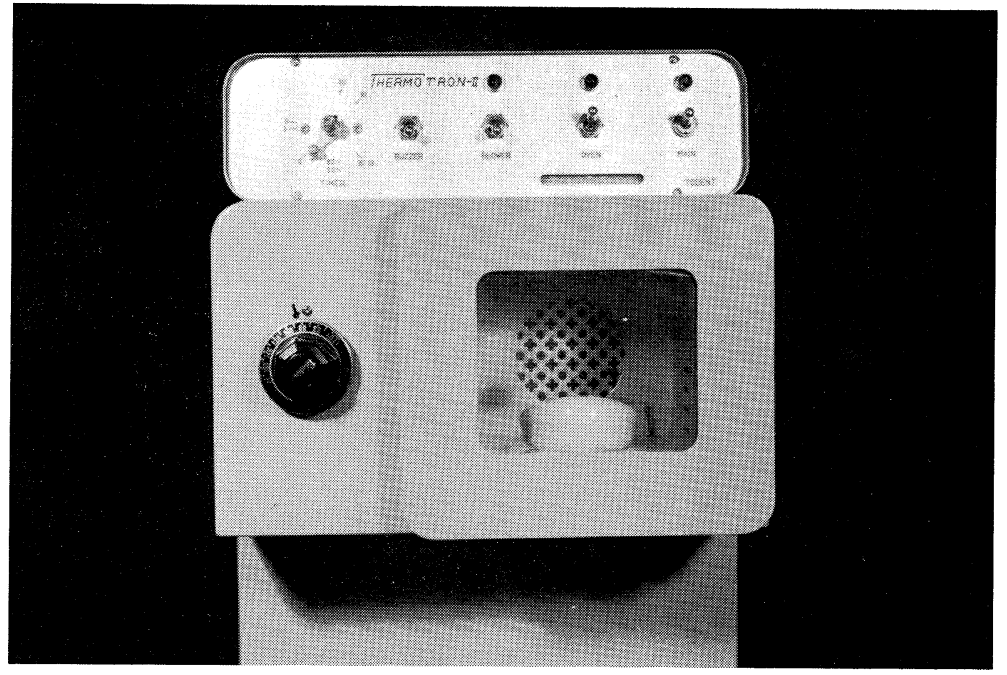

Fig. 16 Vulcanization of glazing agent 


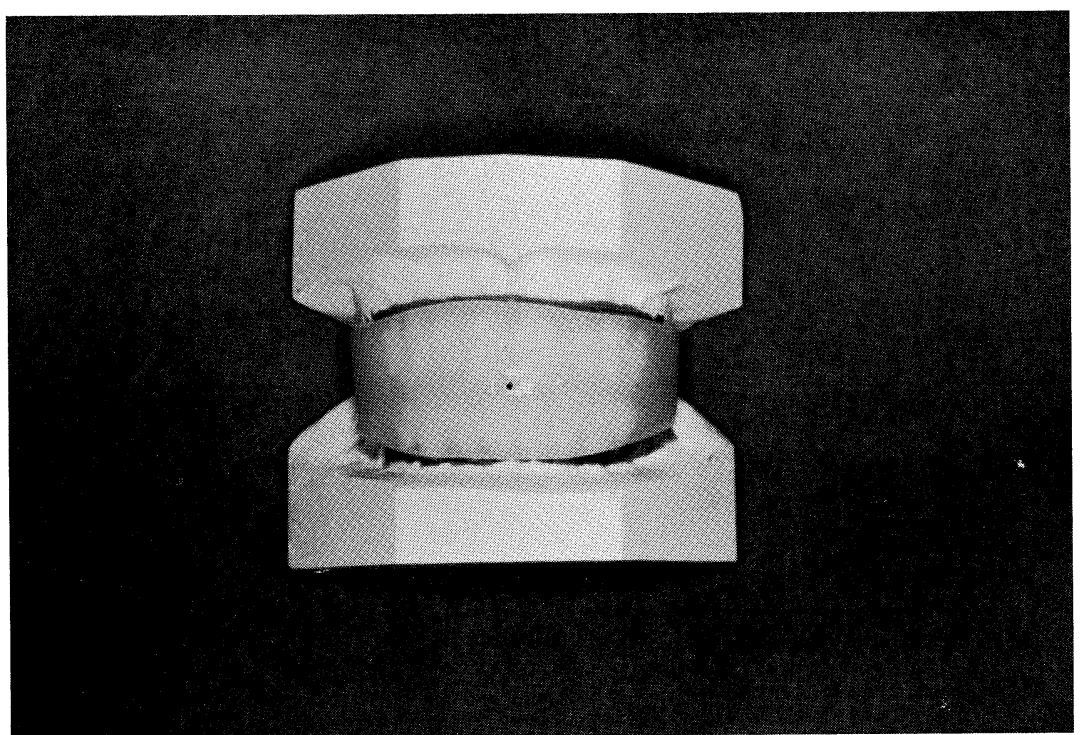

Fig. 17 A tooth positioner in position on the set-up model

\section{Case Reports}

The following are outlines of adaptive cases for tooth positioners, the period to start application, practical instructions and four representative clinical cases selected from more than 80 the authors have previously treated. Case I: maxillary protrusion, Case II: reversed occlusion, Case III: a tooth positioner used as an active retainer, and Case IV: a tooth positioner used in the process of periodontal treatment.

1. Adaptive cases

Adaptive cases for tooth positioners are malocclusions mainly due to odontogenic and functional factors, of which careful analysis and accurate diagnosis are required.

Adaptive cases are as follows: odontogenic and functional maxillary protrusion, mandibular protrusion, deep overbite, cross-bite, denture guidance, adjustment of slightly rotated teeth and inclined teeth, closure of spaces between teeth, adjustment for preferable intercuspal relationships and retention.

2. Period to start application

Orthodontic treatment is most frequently performed in the mixed dentition period, which is considered to be the most suitable period to start treatment. So it is in the case of tooth positioners whose clinical effect is heightened when applied in this period.

3. Practical instructions

When removable appliances such as tooth positioners are applied, the patients' cooperation is urgently required, so much so that parents should be well informed as to the purpose and meaning of such appliances. 
The longer the tooth positioner is applied the better. The orthodontic force of the tooth positioner depends upon its rubber-like elasticity that gives a continuous light force to the teeth. Patients, therefore, are requested to come once a month for the following checks: whether the appliance is being used correctly, kept clean or damaged and when treatment should proceed to the next step. The orthodontic force should be adjusted by the selection of materials in accordance with the amount of tooth movement on the set-up model.

4. Case reports

1) Case I

This was a girl, 10 years and 6 months of age on her first visit. Her chief complaint was protrusion of the upper incisors (Fig. 18). The occlusal findings were of an Angle Class I, $6 \mathrm{~mm}$ overjet.

From the cephalometric analysis results, it was diagnosed as maxillary protrusion mainly caused by an odontogenic factor due to excessive labial inclination of the upper incisors.

The treatment plan was to perform lingual movement and space closure of the upper incisors. That is, in the 1st stage: space closure and improvement of the overbite and overjet, in the 2 nd: achievement of a preferable intercuspal position, and in the 3rd: retention. A tooth positioner was prepared for these purposes. A set-up model was also prepared in accordance with the 3 stages of the treatment plan.

Treatment required 10 months in the 1 st and 2 nd stages and 7 months in the 3rd (observation period).

Fig. 19 shows the tooth positioner mounted in the oral cavity in the 1st stage of treatment. In such a remarkable case of maxillary protrusion, the maxillary portion of the tooth positioner should have some slits to divide its orthodontic force so that the lighter force can be given to the teeth[5].

Fig. 20 shows the oral cavity after treatment: the upper incisors moving in the lingual direction, the spaces closing, the overbite and overjet improved and the intercuspal position becoming preferable. The results proved to be satisfactory.

2) Case II

This was a boy, 9 years and 8 months of age on his first visit. His chief complaint was lower lip protrusion (Fig. 21). The occlusal findings showed an Angle Class III tendency. The upper right and left central incisors and the lateral incisors showed reverse overjet. Again, from the fact that a construction bite could be taken with the mandible retracted, it was diagnosed as functional reverse occlusion. Cephalometric analysis also disclosed a slight inferior growth of the maxilla.

Like Case I, the treatment was planned in 3 stages. The 1 st stage was to improve the malalignment of the anterior teeth as quickly as possible and to remove the obstruction of premature contact. The labial expansion of the 4 upper incisors and the lingual movement of the 4 lower incisors were performed for rearrangement. In the 2nd stage, a set-up model was prepared for the purpose of improving the molar occlusal relationship and to guide the eruption of the buccal segments. Using a model with the anterior overlap improved, the upper and lower first molars were rearranged to be in the normal position. At the same time, the missing areas of the right and left deciduous 2nd molars were filled with wax equivalents of permanent 

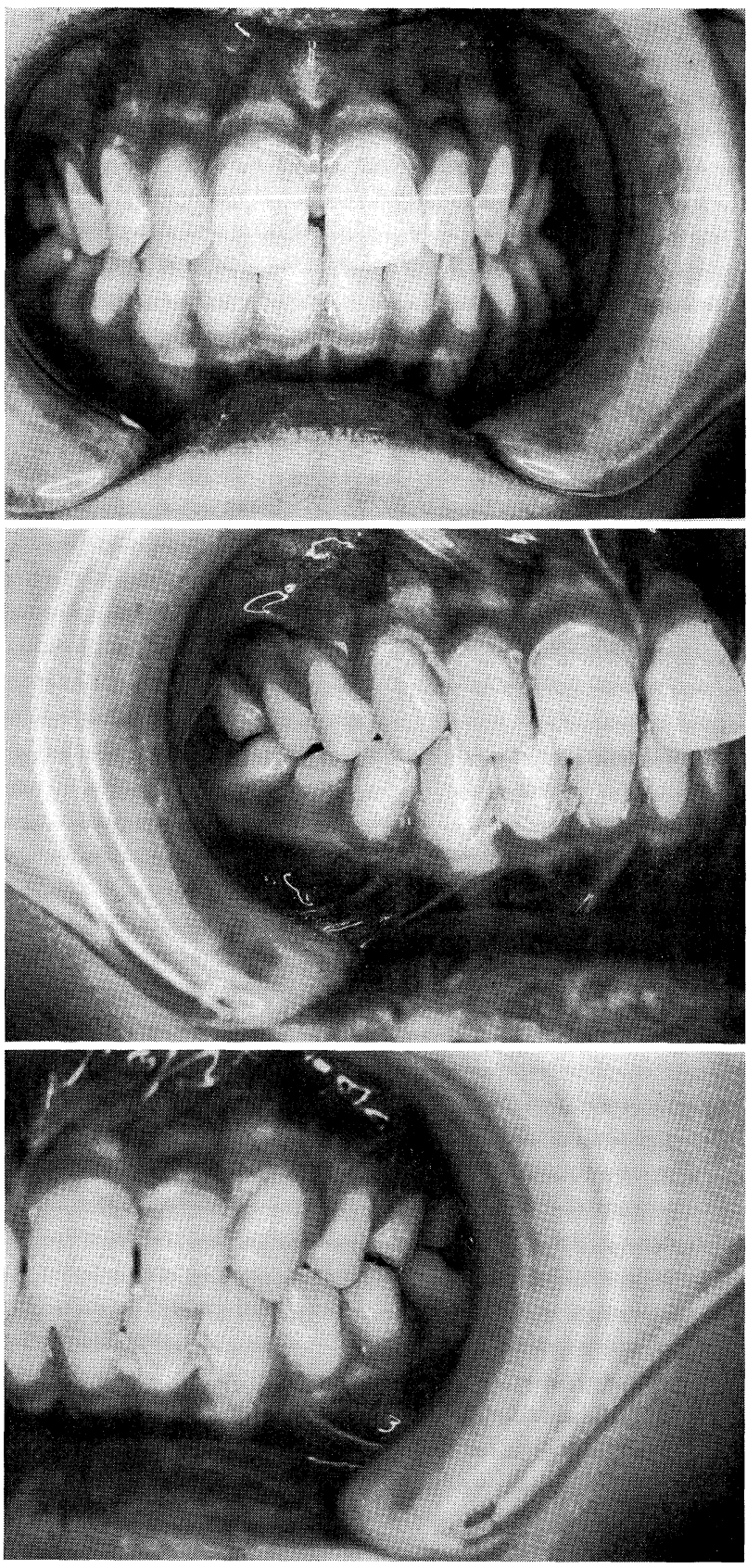

Fig. 18 Case I (Top) Anterior view before treatment (Center and Bottom) Lateral views before treatment 


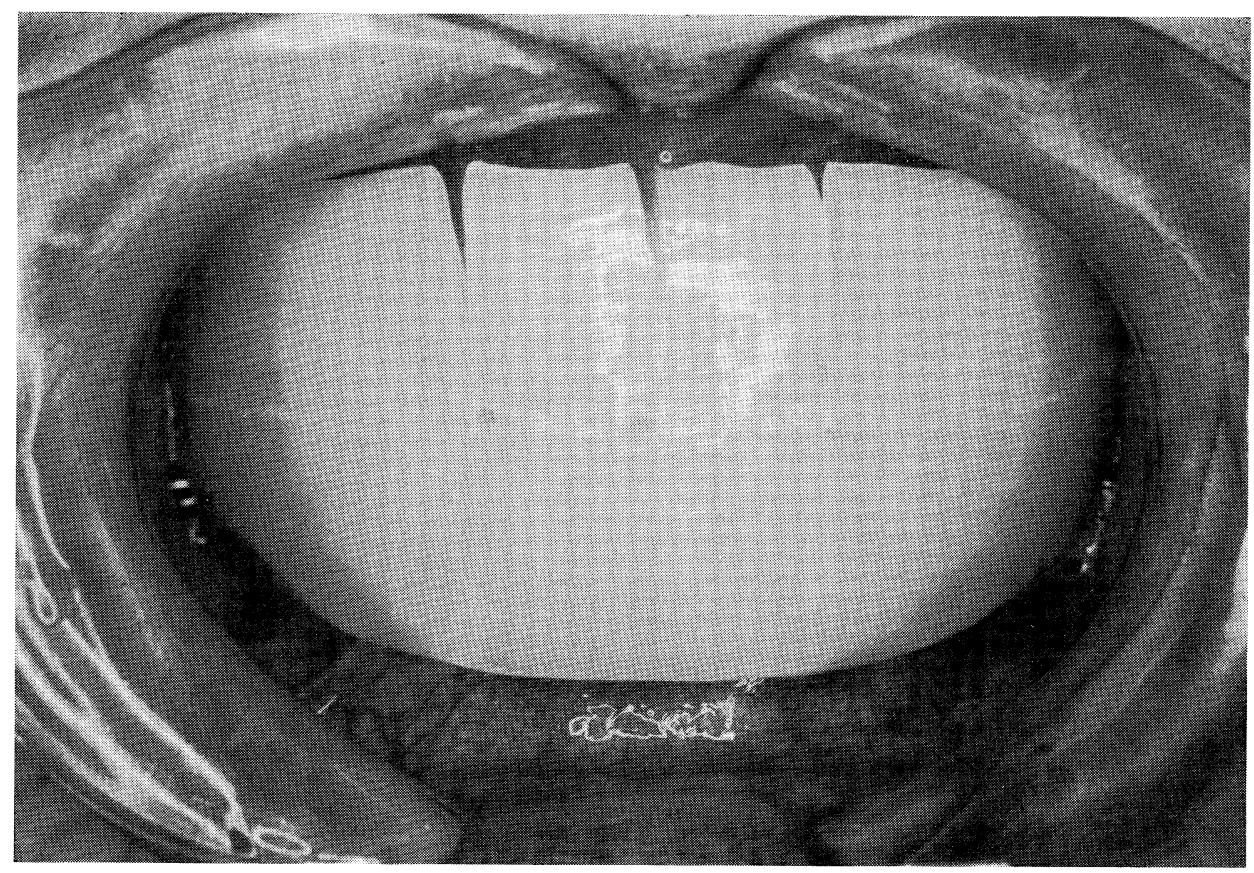

Fig. 19 A tooth positioner with slits

crowns that would erupt later to guide the eruption of the buccal segments.

Fig. 22 shows the oral cavity a month after the tooth positioner was mounted. The overlap of the 4 upper incisors has improved.

Fig. 23, the oral cavity after 15 months showing a preferable anterior occlusal relationship. Hereafter, the treatment is expected to proceed to the 3rd stage, final retention, after the eruption of the lower mandibular second premolars.

3) Case III

This was a case in which a tooth positioner was used as an active retainer in a boy, 9 years and one month of age on his first visit. His chief complaint was lower lip protrusion diagnosed as Angle Class III. The full band system was applied to the treatment and the active treatment period was 19 months. The purpose for the tooth positioner in this case was to improve and retain the intercuspal position of the buccal segments (Fig. 24). A stable occlusal relationship was obtained 3 months after the application of the tooth positioner and the total retention period was 8 months (Fig. 25).

4) Case IV

This was a 33-year-old man for whom a tooth positioner was used for the purposes of closing the spaces between his teeth, improving the intercuspal positions and reducing the patient's feeling of a double protrusion (Fig. 26, top).

This is one of the clinical cases most frequently seen, in which a malocclusion such as malposition of the teeth and axiversion causes and aggravates periodontal disease. In such cases, the malocclusion should be improved to promote treatment 

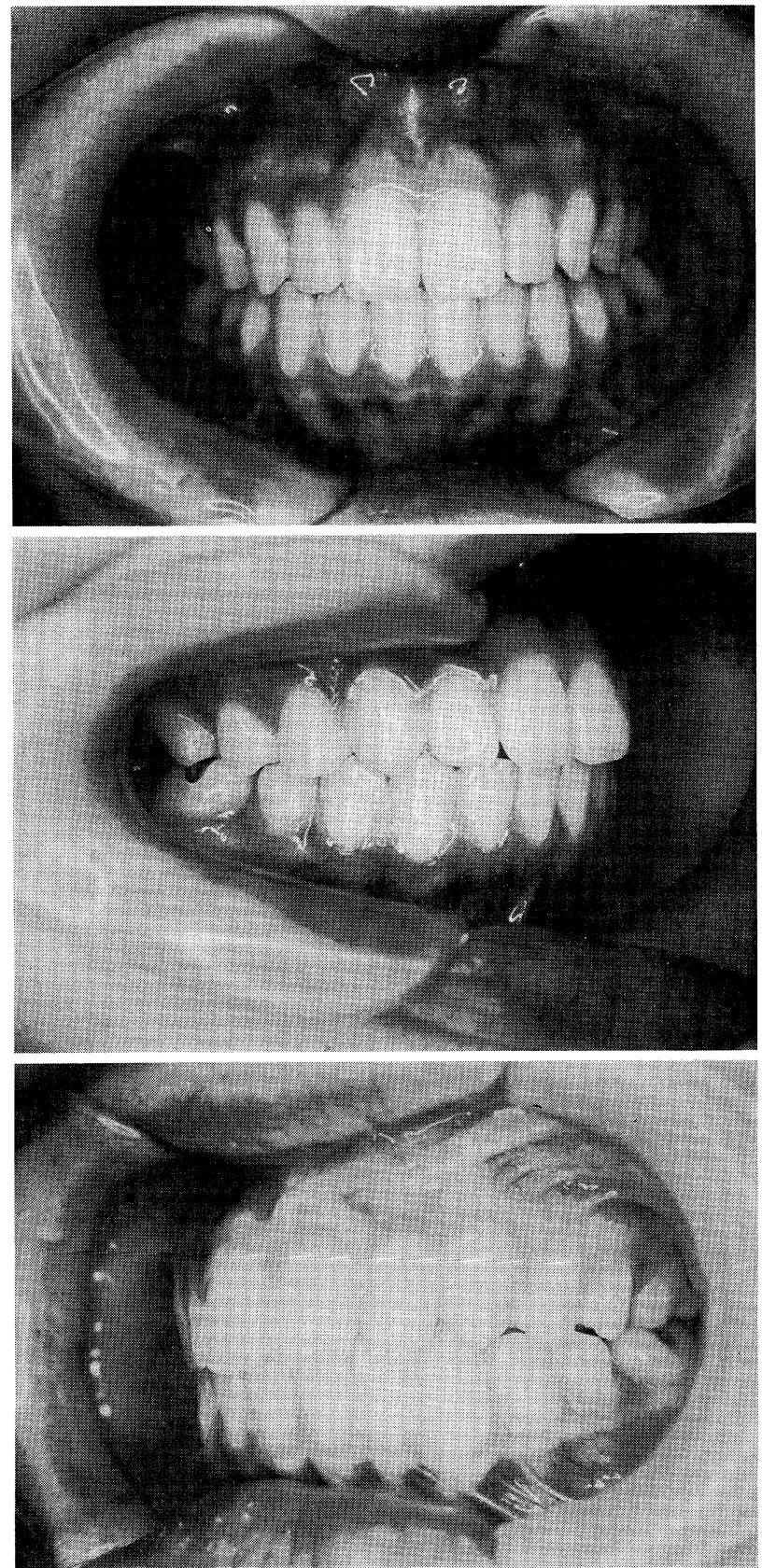

Fig. 20 Case I (Top) Anterior view after treatment (Center and Bottom) Lateral views after treatment 

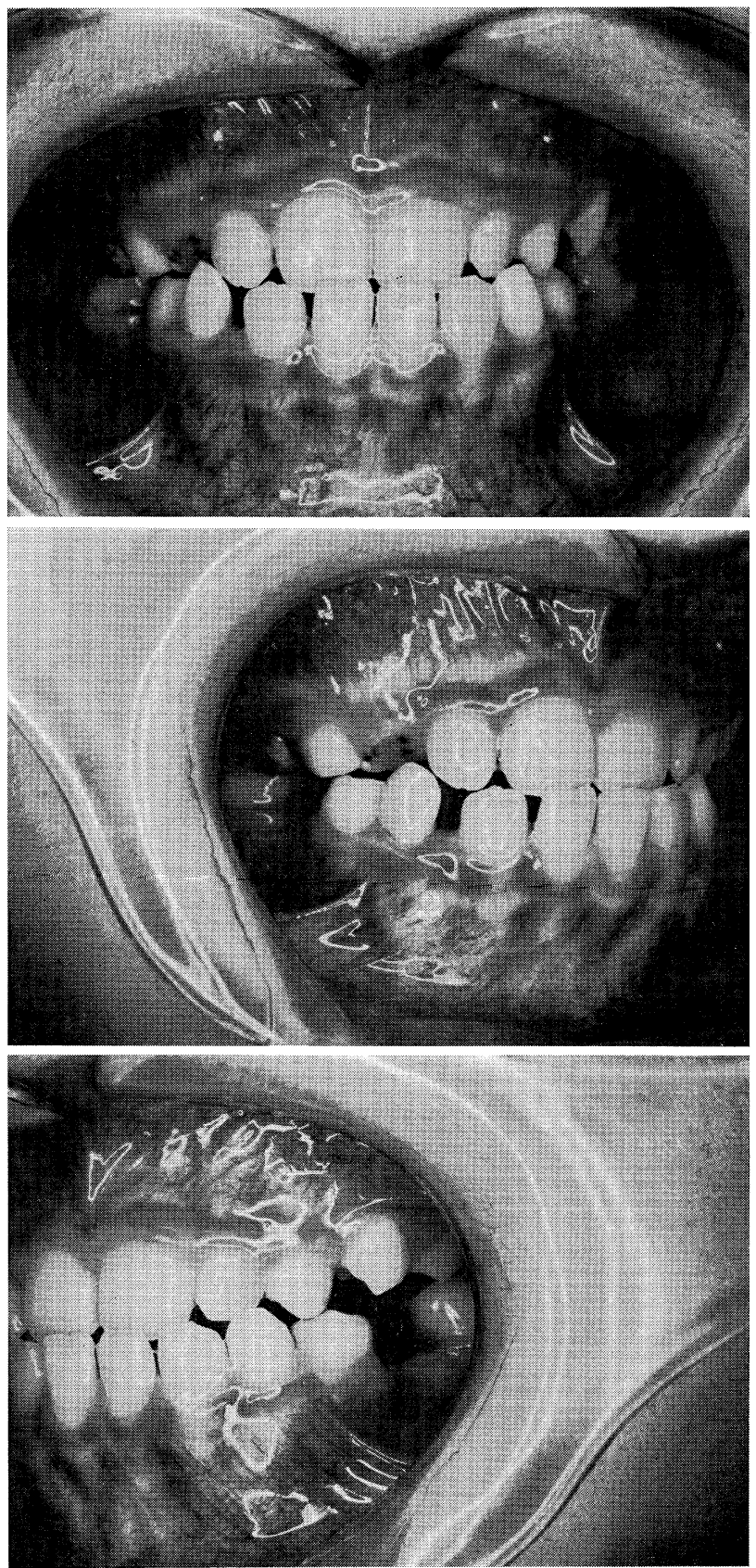

Fig. 21 Case II (Top) Anterior view before treatment (Center and Bottom) Lateral views before treatment 


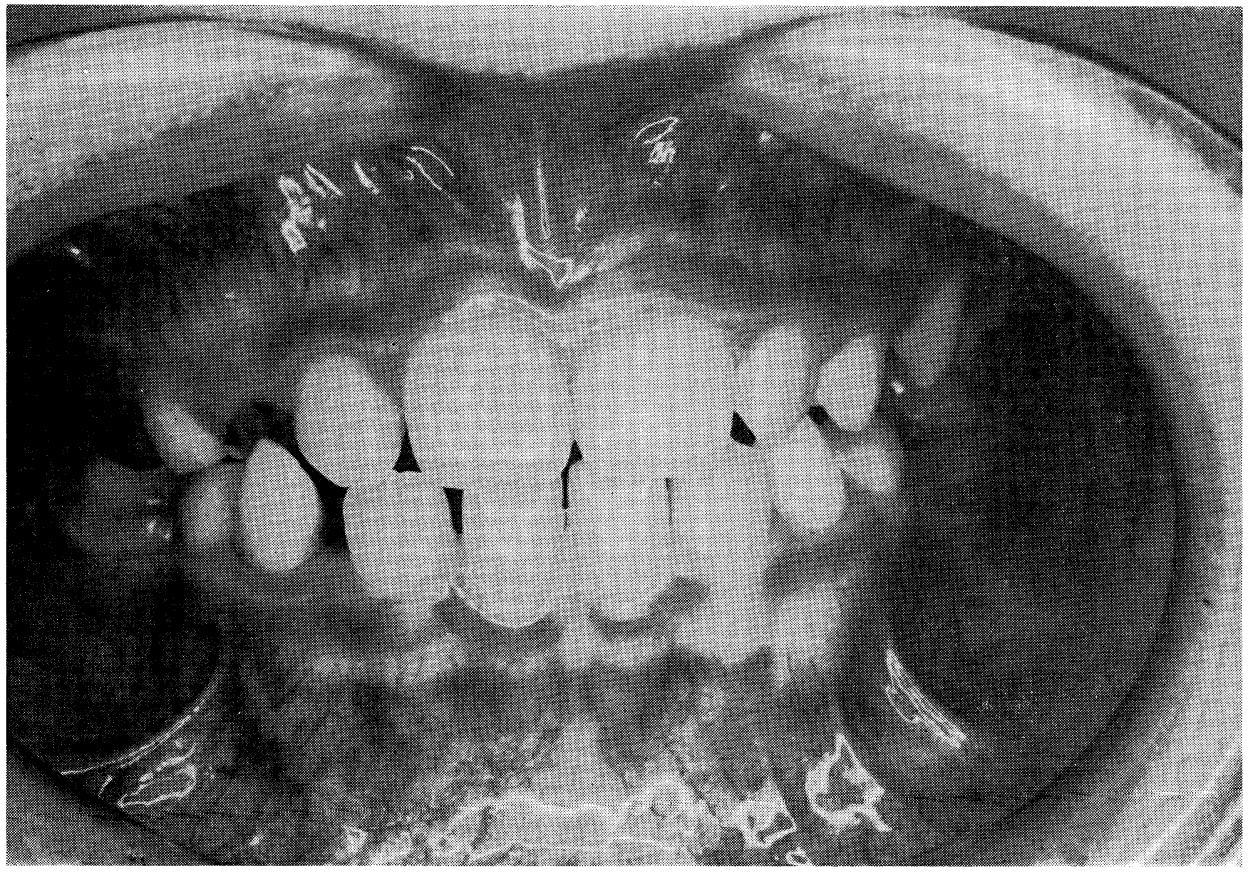

Fig. 22 Case II Anterior view after one month

of the periodontal disease. Fundamental treatment of the disease is of course necessary, but its effects are heightened by the simultaneous use of orthodontic treatment.

Fig. 26, top, shows the oral cavity immediately after fundamental treatment for the periodontal disease was finished. The anterior overlap is insufficient, double protrusion and spaces between the teeth are observed and the intercuspal position of the buccal segments is unstable.

The treatment plan was to improve the abnormalities shown above, to give preferable influence not only to the anterior teeth but also to the periodontal tissues of the molar teeth and to secure the remarkable effects of treatment, functionally and aesthetically. Patients are always very much interested in aesthetic improvements. In the present case, from the beginning, the set-up model was arranged to show the normal overlap.

Fig. 26, bottom, the oral cavity 4 months after the application of the tooth positioner showing that a stable occlusal relationship was obtained. The treatment was followed by fixation through periodontal treatment.

As shown above, the present material has excellent rubberlike elasticity and a wide area of action which makes it possible to move the teeth to a greater degree as compared with the existing materials for tooth positioners. Considering these merits and its preferable manipulability, wide application would be expected regarding tooth movement. 

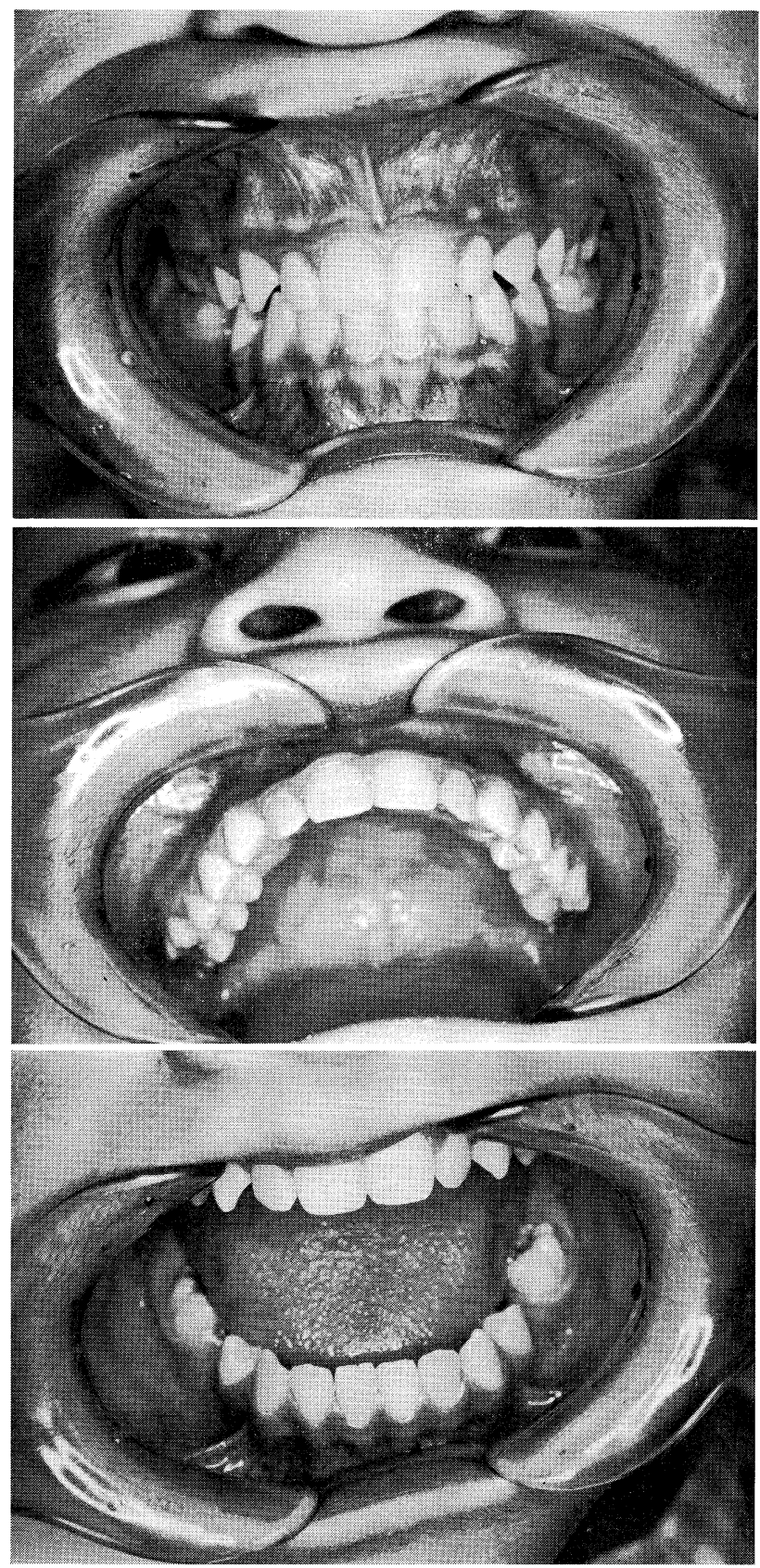

Fig. 23 Case II (Top) Anterior view after 15 months (Center and Bottom) Occlusal views after 15 months 

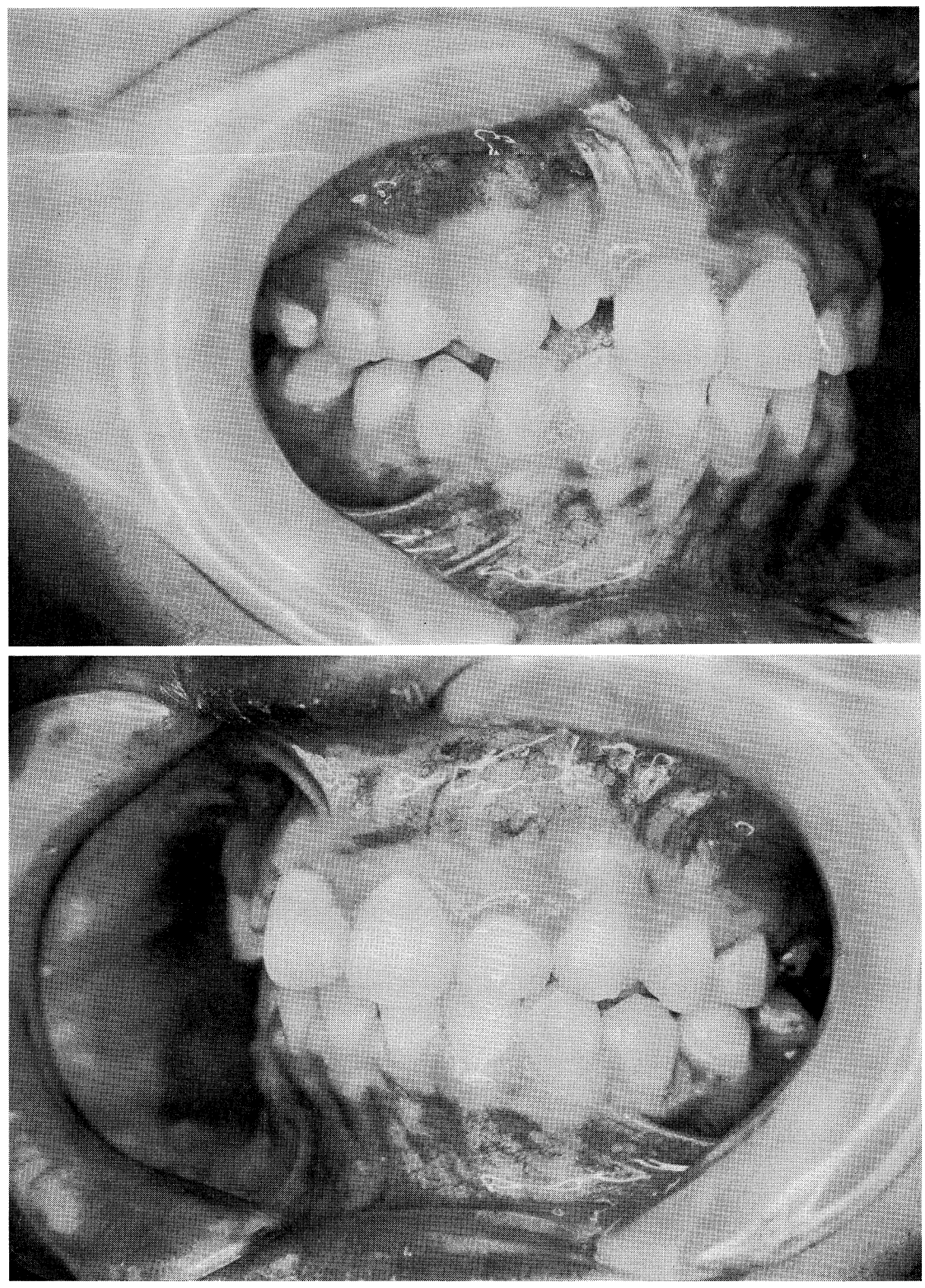

Fig. 24 Case III (Top and Bottom) Lateral views before setting of the tooth positioner 

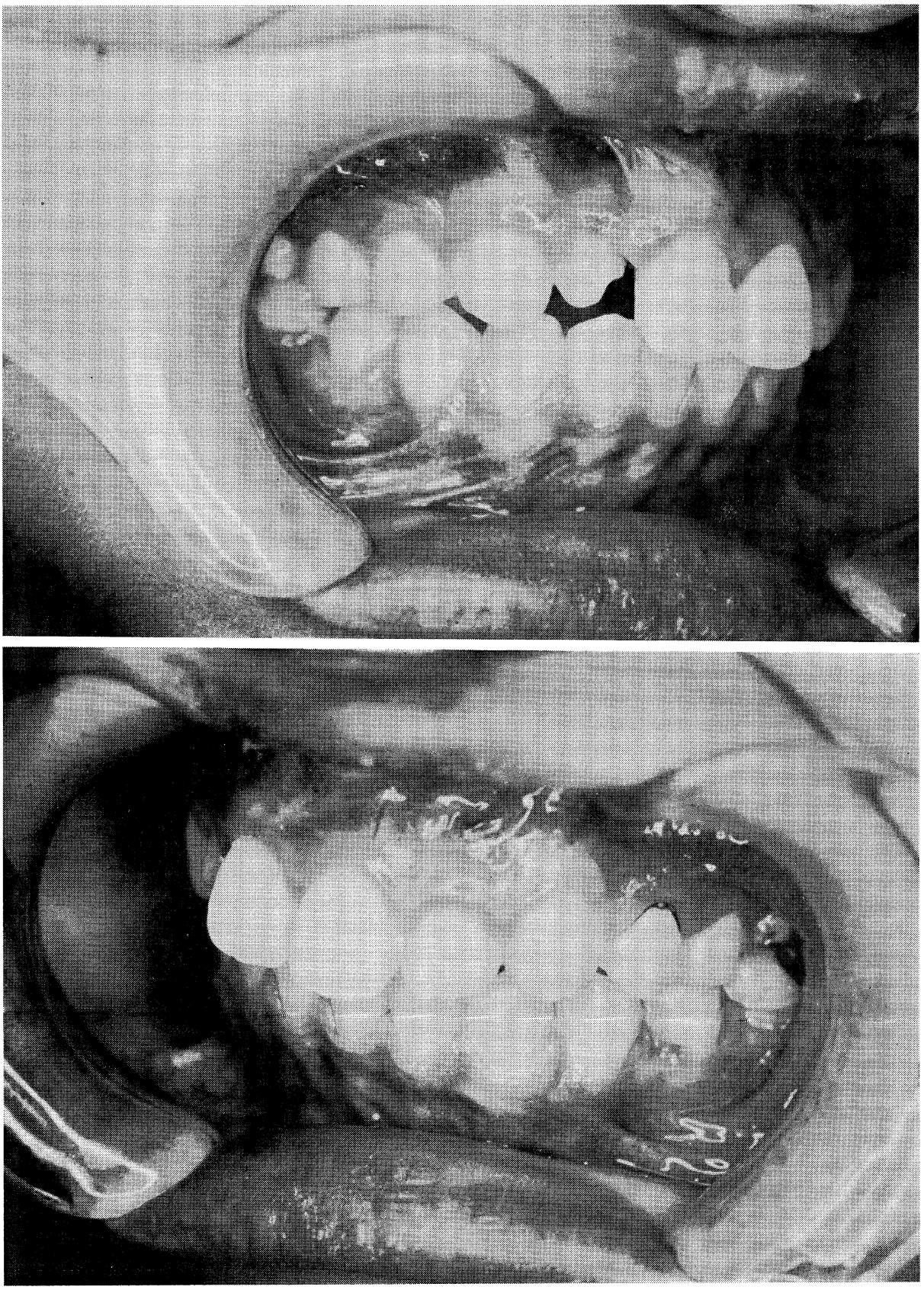

Fig. 25 Case III (Top and Bottom) Lateral views after treatment with the tooth positioner 

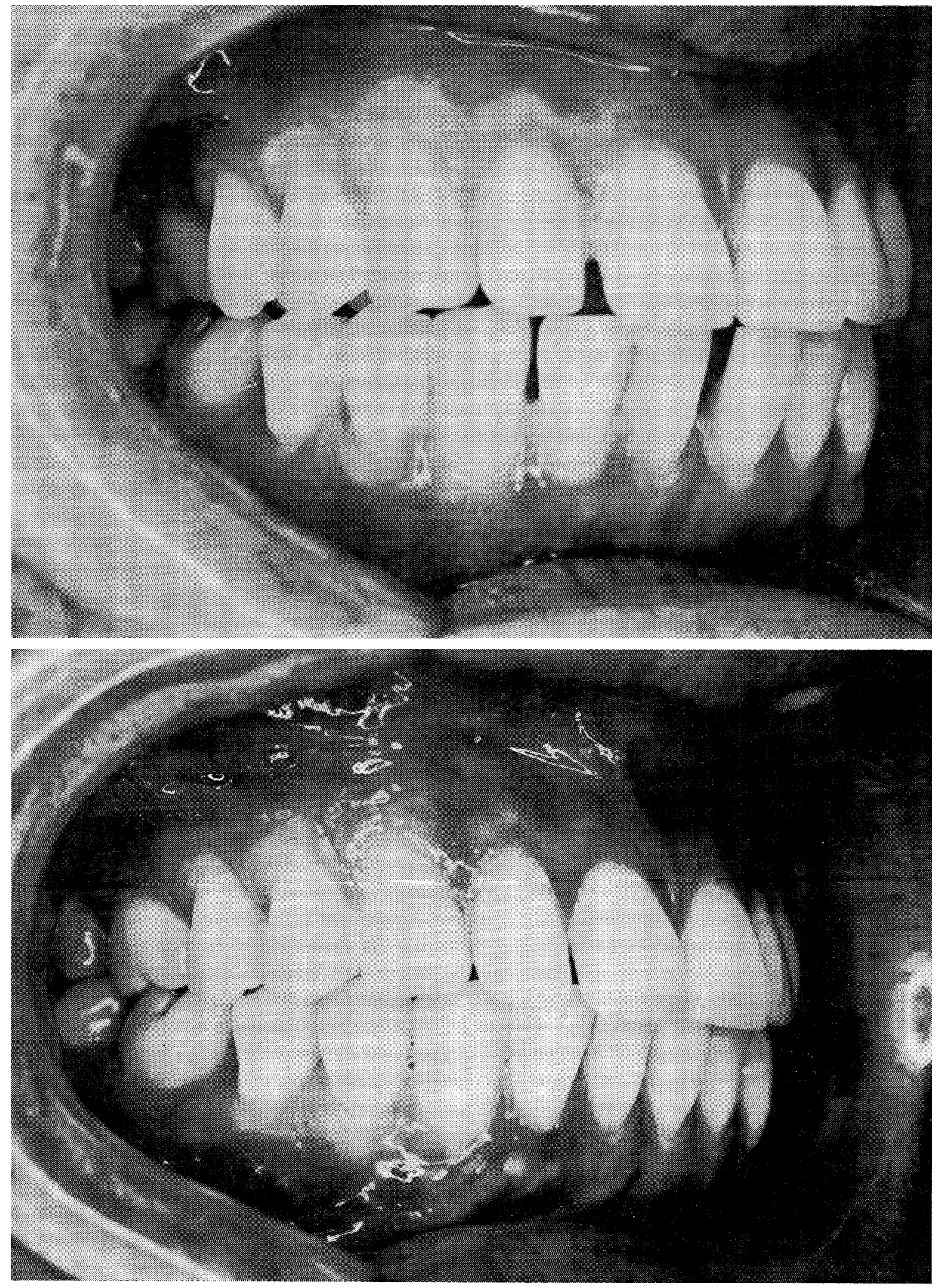

Fig. 26 Case IV (Top) Lateral view before treatment with the tooth positioner (Bottom) Lateral view after treatment with the tooth positioner 


\section{Conclusion}

This paper introduced the properties of LTV vinyl silicone rubber as a new type of dental material, the method for preparing tooth positioners with this material and some case reports. As we have seen, the present material is easy to manipulate and has excellent physical properties especially in elasticity. Again, because the present material has preferable adhesiveness to methacrylate resin[13], it is possible to make various kinds of dental appliances with this material used together with denture relining material, denture splint material and other methacrylate resins. Its wide application, therefore, would be expected.

\section{References}

[1] YoshiI, O.: Studies on orthodontic rubber materials (Part 3); J. Stomatol. Soc. Jpn., Vol. 40, 103-121, (1973). (in Japanese)

[2] Nishiyama, M., Kamada, K. and Horiuchi, S.: A new construction of tooth positioners with LTV vinyl silicone rubber; J. Nihon Univ. Sch. Dent., Vol. 19, 93-102, (1977, published in 1979).

[3] Nishiyama, M. et al.: Studies on tooth positioner materials-Application of LTV vinyl silicone rubber-; Nihon Univ. dent. J., Vol. 53, 491-498, (1979). (in Japanese)

[4] Yoshi, O.: New orthodontic device-dynamic positioner (D.P)-I. Approach to the proposal of D.P and transparent silicone rubber; The Nippon Dental Review, No. 452, 61-74, (1980). (in Japanese)

[5] YoshiI, O.: New orthodontic device-dynamic positioner (D.P)-II. Practical application and construction of D.P; The Nippon Dental Review, No. 454, 107-130, (1980). (in Japanese)

[6] YoshiI, O.: New orthodontic device-dynamic positioner (D.P) - III. Case reports of reversed occlusion; The Nippon Dental Review, No. 457, 146-164, (1980). (in Japanese)

[7] YoshiI, O.: New orthodontic device-dynamic positioner (D.P)-III. Case reports of reversed occlusion (Part 2); The Nippon Dental Review, No. 458, 112-129, (1980). (in Japanese)

[8] Kesling, H. D.: The philosophy of tooth positioning appliances; Amer. J. Orthodont., Vol. 31, 297-304, (1945).

[9] Kesling, H. D.: Coordinating the predetermined and tooth positioner with conventional treatment; Amer. J. Orthodont., Vol. 32, 285-293, (1946).

[10] Sugimura, H. et al.: Materials for tooth positioners; J. Jap. Orthod. Soc., Vol. 25, 106-114, (1966). (in Japanese)

[11] Prescott, M. A. and Fartman, A.: Construction of silicone rubber tooth positioners in your own laboratory; J. Practical Orthodont., Vol. 2, 456-460, (1968).

[12] Wells, N.E.: Application of the positioner appliance in orthodontic treatment; Amer. J. Orthodont., Vol. 58, 351-366, (1970).

[13] Nishiyama, M. et al.: Studies on vinyl silicone rubber-Its composition and basic properties-; $J D M A$, Vol. 35, 370-377, (1979). (in Japanese) 